\title{
Polarimetric Imaging for Air Accident Investigation
}

\author{
G.J.Privett, M.D.Ashe, M.J.Greaves*, D.Holland ${ }^{+}$, L Davidson. \\ Defence Science and Technology Laboratory, Porton, Wiltshire, SP4 OJQ, United Kingdom. \\ "Cranfield University, Cranfield, Bedfordshire, MK43 0AL, United Kingdom. \\ ${ }^{+}$NIEC, RAF Brampton, Huntingdonshire, PE28 4QH, United Kingdom.
}

\begin{abstract}
We report a trial wherein a simple 4 CCD visible-band Polarimetric Imaging (PI) camera was fielded against aircraft debris distributed across an arid terrain, a littoral region and a small number of maritime debris targets

A debris field realistically simulating an aircrash and a debris grid of aircraft remains were observed from an air platform flying in dry and sunny conditions.

We report PI utility in support of air accident investigation by an enhanced ability to successfully locate small targets within the scene via the use of colour enhanced and decorrelated intensity PI products. Our results indicate that handheld PI capability may represent an effective low cost, upgrade and augmentation option for existing and future imaging systems that would support air accident investigators and assist in the cueing of more sophisticated assets and/or analyst attention.
\end{abstract}

\section{KEYWORDS}

Polarimetric imaging, passive, visible band, air accident investigation.

\section{INTRODUCTION}

The defining attributes of light from any source are intensity, colour and polarisation (Schott 2009). The first two of these are familiar to us courtesy of our eyes and are exploited by virtually all commercial available imaging systems. By comparison, polarisation state is only very weakly perceived by human eyes (Minnaert 1993, O'Meara 2005) and so it is perhaps no coincidence that only in the last decade or so that frame rate Polarimetric Imaging (PI) cameras have become available commercially - more than 100 years after the first movie camera was developed.

Polarimetric information is used by numerous bees, cephalopods and shrimp to navigate their environments, identify prey and locate neighbours (Shashar 1996 and 1998). In a similar manner this information has further benefits in the human remote sensing world beyond those derived from colour and intensity information. It has been used to identify geological features (Dollfus 1974) but it may be suited to locating some classes of material (Schott 2009, Zhao 2009) in a morphologically and spectrally cluttered scene.

In the visible band this discriminative potential arises because some materials have a tendency to polarise (or depolarise) light that is incident upon them. Unpolarised light from the Sun, unpolarised light reflecting from clouds and partially polarised light from a blue sky all interact with the material surface to generate a partially polarised reflected element that can, in the right circumstances, give rise to a contrast with the background terrain. Importantly, PI provides this additional information while simultaneously providing a normal, electro-optical (EO) image of the same scene as a by-product.

This paper describes a trial wherein a simple Dstl constructed visible band polarimetric camera was demonstrated to have useful capability in support of air accident investigation.

Electro-Optical and Infrared Systems: Technology and Applications IX, edited by David A. Huckridge, Reinhard R. Ebert, Proc. of SPIE Vol. 8541, 85410H · @ 2012 SPIE · CCC code: 0277-786/12/\$18 - doi: 10.1117/12.978936

Please refer to any applicable publisher terms of use.

Proc. of SPIE Vol. $854185410 \mathrm{H}-1$ 


\section{AIR ACCIDENT INVESTIGATION TRIAL}

The National Imagery Intelligence Centre (NIEC) provides imagery analysis support to Boards of Inquiry into military air accidents. NIEC staff and co-opted specialists from the UK civil Air Accidents Investigation Branch (AAIB) visit crash sites and carry out extended analyses including debris collection and wreckage location plotting. However, it has been noted that crash sites have occurred in locations where the access to the ground has been confined to first-response teams and aircraft wreckage collection has not been viable.

Consequently, imagery taken from the attending aircraft can become a crucial source in the forensic aspects of the accident investigation. In the absence of formal guidelines to assist the Royal Air Force (RAF) photographers in carrying out their role, representatives from NIEC, Cranfield University and the AAIB formed a virtual team that has mounted a series of trials creating simulated wreckage sites against which proposed Standard Operating Procedures (SOP) for use by photographers attending crash scenes could be developed and tested.

The first trial, K1, took place at Cranfield Airfield in 2007 and was followed by K2 and K3 in 2008. These led to a draft set of procedures to ensure that imagery collections from attending aircraft or subsequent commercial satellite imagery (CSI) were optimised. Unfortunately, these trials were somewhat hampered by poor weather and background conditions limited to a single type of environment (maritime temperate). Dstl took part in the K3 and $\mathrm{K} 4$ trials with a remit to explore augmenting the baseline EO sensors with other systems. Part of this involved constructing a simple PI imager as a first look at the potential of PI data. These trials presented an unusual opportunity to examine an extensive groundtruthed scene including a large variety of aircraft material types. For demonstration of concept purposes, the camera system Dstl put together was a simple handheld PI sensor (PC4) that had a low frame rate (1Hz) but was laptop powered, lightweight and constructed from commercial off the shelf components. This made it highly deployable and allowed us to test a range of options for its use. Trial K4 was held during August 2009 at RAF Akrotiri, Cyprus.

The PI and CSI results covered aircraft debris distributed across highly arid terrain, debris within the littoral region and also a small sample of maritime debris. Additional tools and techniques, including a decorrelated intensity product, have been developed that would considerably aid an imagery analyst in exploiting PI imagery. These tools were written in IDL and Envi and images stored as Flexible Image Transport System (FITS) files to allow easy assessment. The goal for all of this was to provide a simple, flexible and low cost augment to aid in the investigation of a crash site.

\section{THE TRIAL ACTIVITY}

The trial was undertaken at Cape Zevgari, Akrotiri on the Sovereign Base Area, Cyprus during August 2009. Akrotiri provided a convenient location with an arid terrain and good weather fortuitously combined with the full support infrastructure and facilities associated with an RAF base.

A $50 \mathrm{~m} \times 80 \mathrm{~m}$ grid of objects was laid out on the range (Fig. 1), which included approximately 20 pieces of aircraft collected at air crashes investigated by AAIB. These were laid out with 16 square painted metal plates and 5 Perspex squares of various sizes. The aircraft wreckage was selected by staff from Dstl, AAIB, NIEC and Cranfield and contained a range of materials, which are almost always present at an aircraft accident.

\begin{tabular}{|c|c|c|c|c|c|c|}
\hline 1 & $\begin{array}{c}\text { USAF tri- } \\
\text { bar optical } \\
\text { target }\end{array}$ & $\begin{array}{c}\text { Grey steel } \\
4 \mathrm{~m} \times 4 \mathrm{~m}\end{array}$ & $\begin{array}{c}\text { Grey steel } \\
2 \mathrm{~m} \times 2 \mathrm{~m} \\
(45 \mathrm{deg})\end{array}$ & $\begin{array}{c}\text { Grey steel } \\
2 \mathrm{~m} \times 2 \mathrm{~m} \\
(45 \mathrm{deg})\end{array}$ & $\begin{array}{c}\text { Grey steel } \\
2 \mathrm{~m} \times 2 \mathrm{~m} \\
(45 \mathrm{deg})\end{array}$ & $\begin{array}{c}\text { Grey steel } \\
2 \mathrm{~m} \times 2 \mathrm{~m}\end{array}$ \\
\hline 2 & UNUSED & $\begin{array}{c}\text { White } \\
\text { aluminium } \\
4 \mathrm{~m} \times 4 \mathrm{~m}\end{array}$ & $\begin{array}{c}\text { White } \\
\text { aluminium } \\
2 \mathrm{~m} \times 2 \mathrm{~m}\end{array}$ & $\begin{array}{c}\text { White } \\
\text { aluminium } \\
1 \mathrm{~m} \times 1 \mathrm{~m}\end{array}$ & $\begin{array}{c}\text { White } \\
\text { aluminium } \\
0.5 \mathrm{~m} \times \\
0.5 \mathrm{~m}\end{array}$ & $\begin{array}{c}\text { Intentionally } \\
\text { empty }\end{array}$ \\
\hline
\end{tabular}




\begin{tabular}{|c|c|c|c|c|c|c|}
\hline 3 & Aircraft reg & $\begin{array}{l}\text { Orange } \\
\text { aluminium } \\
4 \mathrm{~m} \times 4 \mathrm{~m}\end{array}$ & $\begin{array}{c}\text { Intentionally } \\
\text { empty }\end{array}$ & $\begin{array}{c}\text { Orange } \\
\text { aluminium } \\
2 \mathrm{~m} \times 2 \mathrm{~m} \\
(1 \mathrm{~m} \\
\text { raised })\end{array}$ & $\begin{array}{c}\text { Intentionally } \\
\text { empty }\end{array}$ & $\begin{array}{l}\text { Orange } \\
\text { aluminium } \\
2 \mathrm{~m} \times 2 \mathrm{~m} \\
(2 \mathrm{~m} \text { raised })\end{array}$ \\
\hline 4 & $\begin{array}{c}\text { Aircraft reg } \\
\text { (at 90deg) }\end{array}$ & $\begin{array}{l}\text { Perspex } \\
4 m \times 4 m\end{array}$ & $\begin{array}{l}\text { Perspex } \\
2 m \times 2 m\end{array}$ & $\begin{array}{l}\text { Perspex } \\
1 \mathrm{~m} \times 1 \mathrm{~m}\end{array}$ & $\begin{array}{c}\text { Perspex } \\
0.5 \mathrm{~m} x \\
0.5 \mathrm{~m}\end{array}$ & $\begin{array}{c}\text { Intentionally } \\
\text { empty }\end{array}$ \\
\hline 5 & $\begin{array}{l}\text { Typhoon } \\
\text { canopy } \\
\text { large }\end{array}$ & $\begin{array}{l}\text { Typhoon } \\
\text { canopy } \\
\text { medium }\end{array}$ & $\begin{array}{l}\text { Typhoon } \\
\text { canopy } \\
\text { small }\end{array}$ & $\begin{array}{l}\text { Panel with } \\
\text { stringers }\end{array}$ & $\begin{array}{l}\text { Small } \\
\text { curved } \\
\text { panel }\end{array}$ & $\begin{array}{l}\text { Small } \\
\text { curved } \\
\text { panel }\end{array}$ \\
\hline 6 & $\begin{array}{l}\text { VC-10 tail } \\
\text { panel large }\end{array}$ & $\begin{array}{l}\text { VC-10 tail } \\
\text { panel } \\
\text { medium }\end{array}$ & $\begin{array}{c}\text { Tornado hyd } \\
\text { reservoir }\end{array}$ & $\begin{array}{l}\text { Tornado } \\
\text { flexi fairing }\end{array}$ & $\begin{array}{l}\text { Cylindrical } \\
\text { flange }\end{array}$ & UNUSED \\
\hline 7 & $\begin{array}{l}\text { Phantom } \\
\text { nose u/c } \\
\text { leg and } \\
\text { wheels }\end{array}$ & $\begin{array}{l}\mathrm{U} / \mathrm{c} \text { leg } \\
\text { casting }\end{array}$ & ADR & $\begin{array}{l}\text { Aircraft } \\
\text { seats }\end{array}$ & Misc. pipes & Small panel \\
\hline 8 & $\begin{array}{l}\text { Radar } \\
\text { reflector }\end{array}$ & $\begin{array}{l}\text { Lynx main } \\
\text { blade }(1)\end{array}$ & $\begin{array}{l}\text { Lynx main } \\
\text { blade (2) at } \\
90 \text { deg to } \\
(1)\end{array}$ & Panel & Panel & $\begin{array}{l}\text { Radar } \\
\text { reflector }\end{array}$ \\
\hline
\end{tabular}

Table 1: Description of the debris grid layout.

The test location was on part of a range fenced off from the rest of the base - which had the benefit of restricting access and so avoiding accidental disturbance to the targets from day to day. A debris grid, simulated Harrier crash scene and a Eurocopter sea crash were each accurately simulated. 


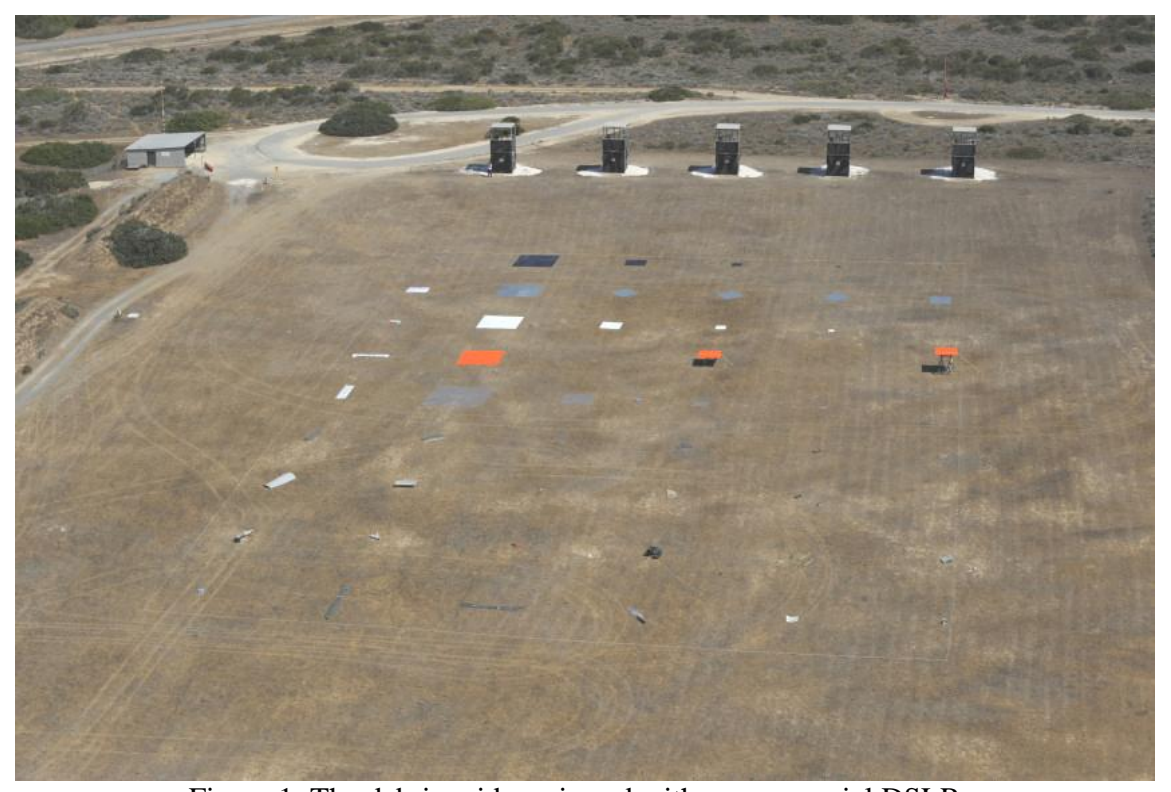

Figure 1: The debris grid as viewed with a commercial DSLR..

The Eurocopter wreckage consisted of a helicopter door, tailplane, rotor and fuselage (Fig. 2). The general location of the items was known, but the specific ground truth from day-to-day varies as some components were moved by the tide/current despite being tied to rocks on the seabed.
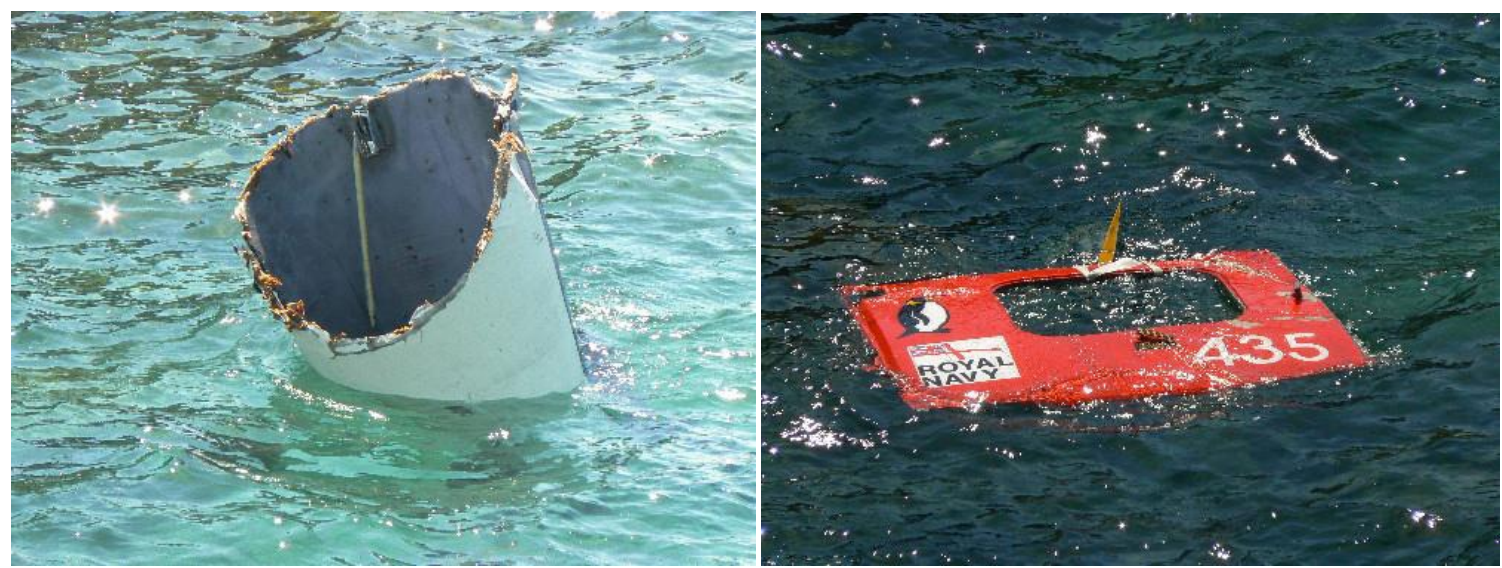

Figure 2: The helicopter tailplane and door.

The Harrier crash scene consisted of tailplane, wing sections, fuel pods, ejector seat, parachute, a partially buried engine and - during some collection activities - a prone volunteer. Plans to burn some of the surrounding soil were abandoned due to brush fire concerns.

The polarimetric imaging was undertaken from the air using a Griffin helicopter operated by 84 Squadron. One person ran the control software on a laptop - ensuring good focus and avoiding image saturation - with another member of staff imaging the grid and wreckage field as they appeared. Focussing information and pointing feedback was conveyed via headset integral intercom.

The imager used was the Dstl-designed four-sensor system employing 4 sets of near identical COTS optics. The lenses employed were standard consumer grade $f 1.8$ with $50 \mathrm{~mm}$ focal length, each fitted with a high quality linear polariser. It was intended that a KG5 infra-red blocking filter would also be employed, but the results obtained suggested this addition to the light path was probably unnecessary and would greatly increase the chance of internal reflections while only slightly improving the efficiency of the polarisers. Each lens was attached to its Charge Coupled Device (CCD) 
camera via a C-mount fitting. The four camera lens systems were mounted on a simple metal frame to provide approximate co-alignment of view.

The 4 CCD cameras used were variants of the Starlight Xpress Lodestar auto-guider sensor (Fig. 3) modified for our purposes. The CCDs were uncooled in this instance to increase battery life. All four were controlled and powered via a single laptop using a USB2.0 interface. Lodestars provide a 16-bit output data format, but the well depth of the Sony Exview monochrome CCD was such as to limit the data to around 15 bits accuracy. The thermal noise in the short exposures ( $50 \mathrm{~ms})$ used, means that 14-bit is a more accurate assessment of the maximum possible image bit depth/dynamic range - though this is further degraded by dust within the optical path. The camera consisted of 4 identical lens/filter/camera systems that viewed essentially the same scene. Each had a polarising filter, which was orientated relative to the camera frame. The orientations used were nominally $0,45,90$ and 135 degrees.

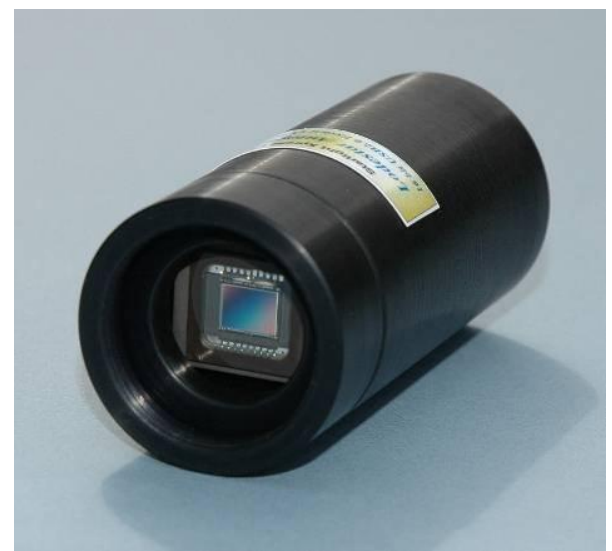

Figure 3: A Lodestar camera. Image courtesy Starlight Xpress.

The initial plan was to circle each target location pausing at the cardinal $(0,90,180,270$ degrees $)$ points relative to the Sun to allow a range of viewing geometries. The helicopter flew in orbits with an elevation angle from the target of approximately 45 degrees. Some variation from circular was inevitable. The flight path equated to a ground sampling pixel size of between $150 \mathrm{~mm}$ and $250 \mathrm{~mm}$. Following the first trial, and with input from the pilot and crew, it was decided that the subsequent targets would be imaged using a slow pass along the circular flight paths. This led to a more stable flight and less vibration to the sensor, but did not significantly change the geometries of the observations derived.

Flights were undertaken on 3 days during the trial. All flights occurred between 10-11 o'clock local time when the Sun was at an altitude of between 58 and 62 degrees - with no clouds present, good visibility, no apparent sea haze and with any morning dew long since evaporated. The wind was light but insufficient to raise obvious dust.

\section{CALCULATING POLARIMETRY}

The linear Stokes parameters, $S_{0}, S_{1}, S_{2}$ were calculated by comparing the 4 contemporaneous images. An $S_{3}$ image relating to the circular polarisation component was not measured in this work and is discussed no further.

The $\mathrm{S}_{0}$ image was formed from the 4 images and looked very similar to the normal EO image of scene - but with improved noise levels. The $S_{1}$ and $S_{2}$ images lacked obvious features when nothing significantly polarised was present in the scene, but shared features with $S_{0}$ when polarised features were present. The quantities were calculated thus:

$$
\mathrm{S}=\left[\begin{array}{l}
\mathrm{S}_{0} \\
\mathrm{~S}_{1} \\
\mathrm{~S}_{2} \\
\mathrm{~S}_{3}
\end{array}\right]=\left[\begin{array}{c}
\mathrm{E}_{\mathrm{x}}^{2}+\mathrm{E}_{\mathrm{y}}^{2} \\
\mathrm{E}_{\mathrm{x}}^{2}-\mathrm{E}_{\mathrm{y}}^{2} \\
2 \mathrm{E}_{\mathrm{x}}^{2} \mathrm{E}_{\mathrm{y}}^{2} \operatorname{Cos} \phi \\
2 \mathrm{E}_{\mathrm{x}}^{2} \mathrm{E}_{\mathrm{y}}^{2} \operatorname{Sin} \phi
\end{array}\right]
$$


Pixel values in $S_{1}$ and $S_{2}$ vary from -1 to +1 . Ex and Ey represent the intensity of light in the two perpendicular directions. The Degree of Linear Polarisation (DoLP), a derived product, was also calculated for each scene.

Decorrelated products were also derived. These were built on a simple assumption, that for unpolarised light the polarimetric filters would simply pass a fixed proportion of the intensity. The signal could therefore be decomposed into an intensity and polarimetric component. A first approximation to this is to assume that any intensity seen $\left(\mathrm{I}_{\mathrm{s}}\right)$ can be broken down into a constant proportion of the intensity representing the unpolarised component that leaks through the filter $(\mathrm{K})$ and a polarised component $(\mathrm{P})$.

$$
I_{S}=(K+P) I_{0}
$$

In general it is not required or desirable to remove the entire intensity component from the data as this reduces the interpretability of the scene as recorded. Therefore an approximation to the model above should provide a simple way to generate an interpretable image that enhances the polarimetric component of the data. If we assume that $\mathrm{K}$ is less variable than $P$ then we can generate a simpler model that states that:

$$
S_{0}=K+P I_{0}
$$

Using a simple least squares fit between the intensity $\left(S_{0}\right)$ band and the raw polarimetric returns we can therefore predict an intensity we expect to see using a scene mean polarimetric value, which can be subtracted. So for scenes where the data is largely unpolarised (most natural scenes) the predicted intensity will be close to the actual intensity for unpolarised materials. Therefore anomalous materials will have enhanced contrast compared to materials similar to the scene mean. The product is therefore just this predicted value of intensity subtracted from the observed intensity. So for each camera band (C) we can find a K, P pair of values that best fit the data and generate a decorrelated product for that camera band (DC)

$$
\begin{gathered}
S_{i}=K_{i}+P_{i} C_{i} \\
\text { Solve to find } \mathrm{K}_{\mathrm{i}} \text { and } \mathrm{P}_{\mathrm{i}} \\
D C_{i}=C_{i}-S_{i}
\end{gathered}
$$

Decorrelated products for each camera band were generated, as were decorrelated Stokes 1 and DoLP products. In general the noise in the DoLP and Stokes 1 was too high to make them particularly useful. There was, however, considerable scope for using the DC products for each camera band.

The data was processed using simple purpose built, scripts that ran within the ENVI software environment. The processing chain went through the phases:

- Removing the impact of thermal noise in the sensor;

- Correcting pixel to pixel sensitivity variations and suppressing artefacts associated with dust particles within the optical train;

- Adjusting the image brightness to correct for minor gain and lens throughput differences from camera to camera;

- Aligning the images from each of the cameras and creating resampled images;

- Calculating the Stokes parameters;

- Calculating decorrelation products; 
- Calculating the DoLP product.

A fully automated image registration was undertaken using a software tool based upon a phase correlation technique. The high degree of correlation between the images made such an approach readily applicable. The registration achieved was generally to an accuracy of a pixel or thereabouts. This degree of accuracy proved to be adequate for our purposes.

An account of the calculations used to generate the Stokes images may be found elsewhere (Schott 2009).

\section{RESULTS}

Despite issues arising from a damaged camera, usable high quality data was collected on 2 of the 3 flight days. Significant collections were made concentrating upon the debris grid with the wreckage/debris field and littoral scene also examined.

The data was processed to generate the Stokes parameters $S_{0}, S_{1}$ and an approximate $S_{2}$ image. The $S_{2}$ images are described as approximate due to the use of images from 3 rather than 4 cameras. However, the excessive bit depth of the data made this less of a limitation than it might otherwise have been.
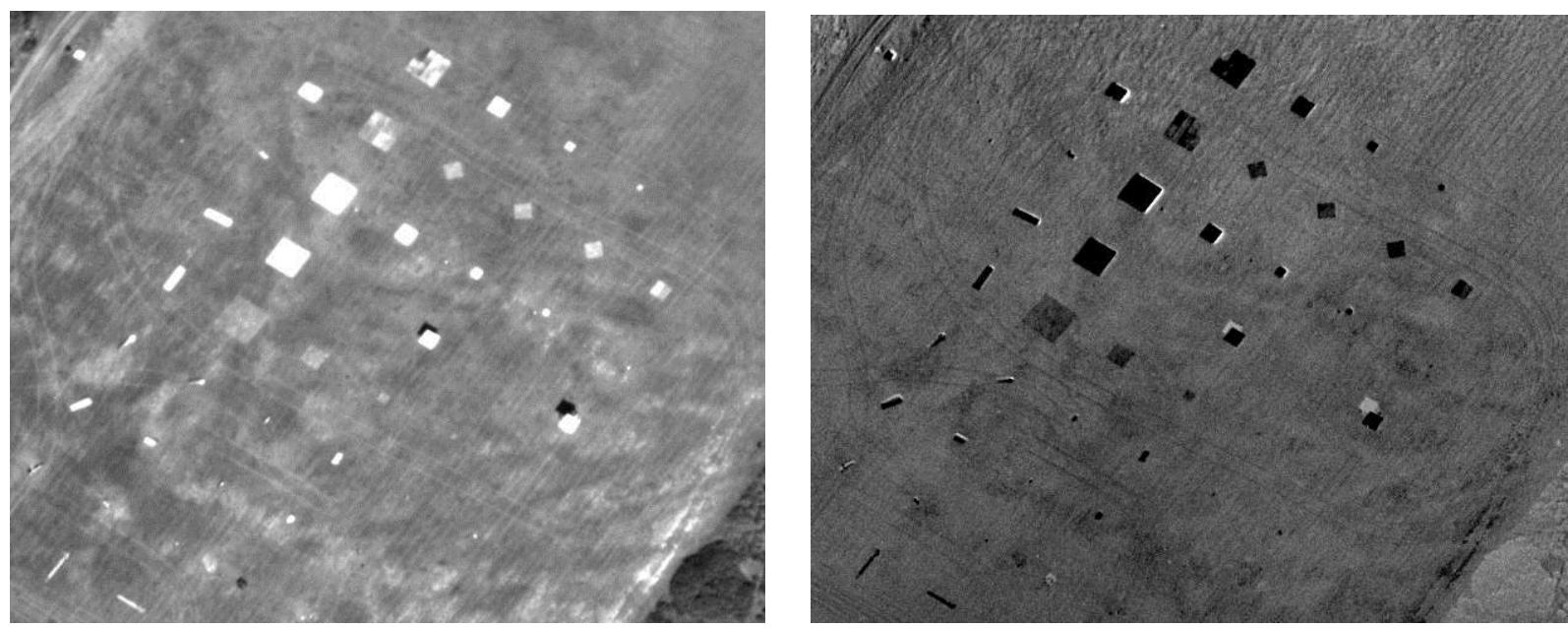

Figure 4: A typical $\mathrm{S}_{0}$ image of the debris grid (left) compared to the corresponding $\mathrm{S}_{1}$ image (right). It is immediately apparent that the contrast of the panels is consistently enhanced in the $S_{1}$ image
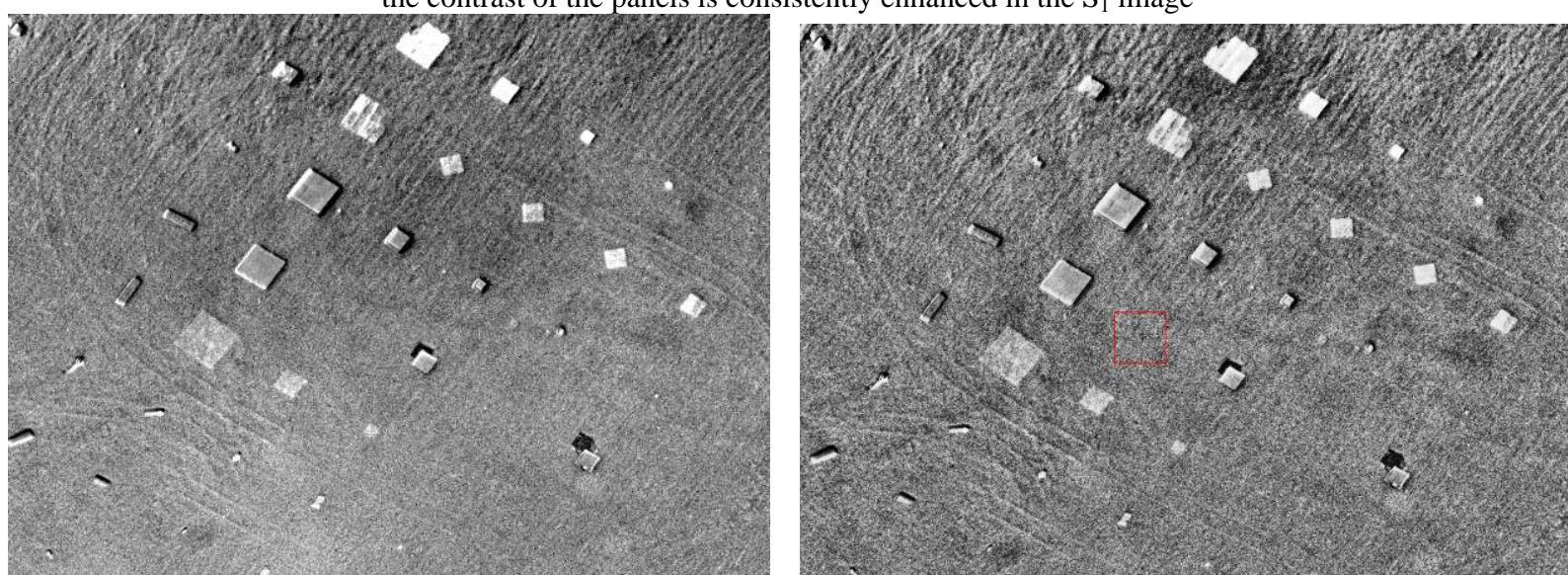

Figure 5: A typical DOLP image of the debris grid (left) compared to the corresponding background demeaned DOLP image (right). The DOLP increases the contrast of individual panels but loses some of the whole-scene discriminatory power of the S1 image 
presented previously. Subtracting a smoothed version of the image improves this. These images have been slightly cropped to reduce edge effects.
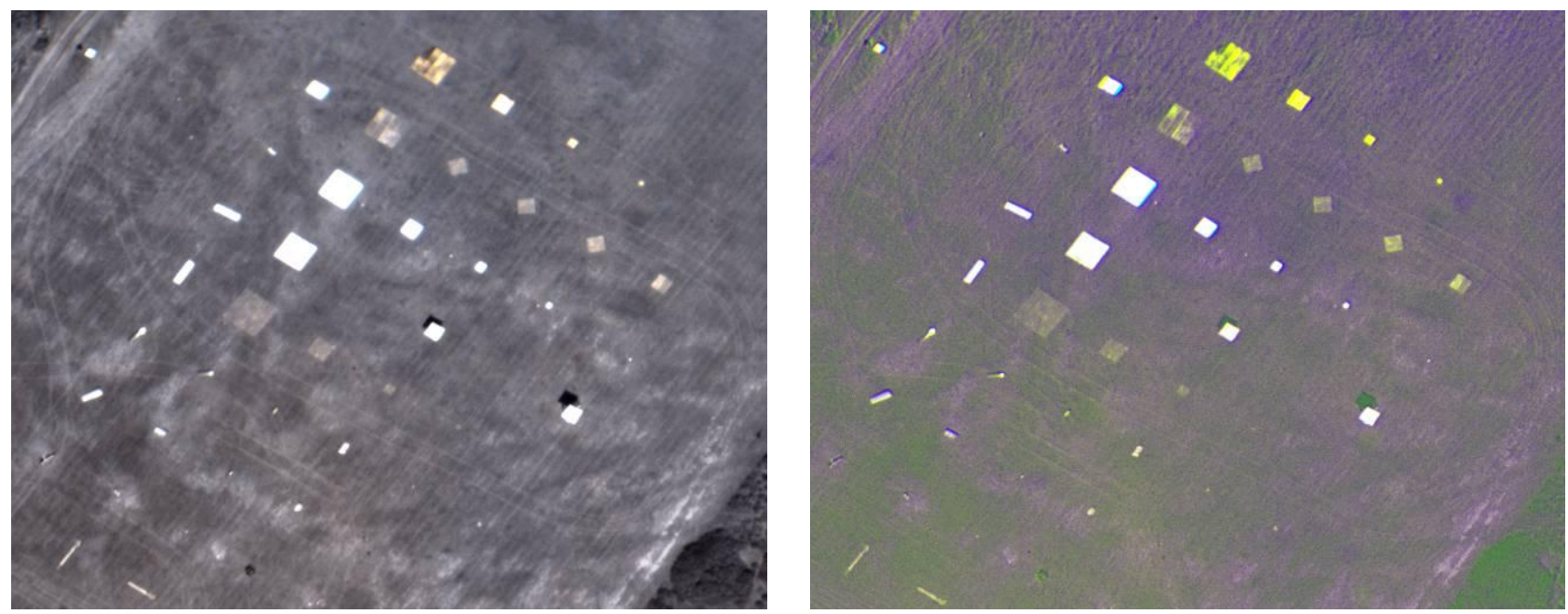

Figure 6:A Colourised PI image of the debris grid and corresponding decorrelated colourised image (right). The colourised product provides a small enhancement to the visualisation as the eye is drawn to the colours more strongly than it is to contrast differences but the decorrelated version has stronger contrast and colouring.

It was noticed that the type of material in each element of the debris grid had an impact upon its visibility in PI images. This was manifested as pixels in the $S_{1}$ and $S_{2}$ images that were either significantly brighter or darker than the image median value or their immediately surrounding pixels. As might be anticipated, much of the scene provided a low polarisation response with some sensor noise and residual dust artefact still present even after full data reduction. By contrast materials such as a Perspex canopy or the sea gave rise to a strongly polarised return. For metals, Perspex, plastic composite and a few painted samples the value of $S_{1}$ and $S_{2}$ associated with them deviated strongly from zero. This information was used to colour the monochrome $S_{0}$ image so that significantly polarised responses were represented by a red or yellow response. This colour information provided an easy cue to those examining the imagery and looking for the grid elements (Fig. 6).

In addition, it was apparent that the geometry of the collection activity had some bearing upon the response generated. The detail of this dependency has not been fully investigated, but it was apparent that at some geometries the smaller objects in a grid line were seen more easily. The response was especially striking with Perspex sheeting where the sheet could completely vanish from $\mathrm{S}_{0}$ imagery at some geometries, but remain visible in the PI.

A favourable geometry was found to allow us to see all the items mentioned in Table 1, even highlighting a radar reflector that was 2 pixels wide against an uneven background. Some of the items were difficult to spot visually on the normal $\mathrm{S}_{0}$ imagery - requiring the use of a local histogram equalisation display.

During the processing it was noticed that strong specular reflections from surfaces could lead to image artefacts generating a trail across the image from a brilliant highly saturated pixel. This has been determined to be due to inadequate clearing of some CCD image registers and the image acquisition software has now been modified accordingly (see figure 7 for an example). 

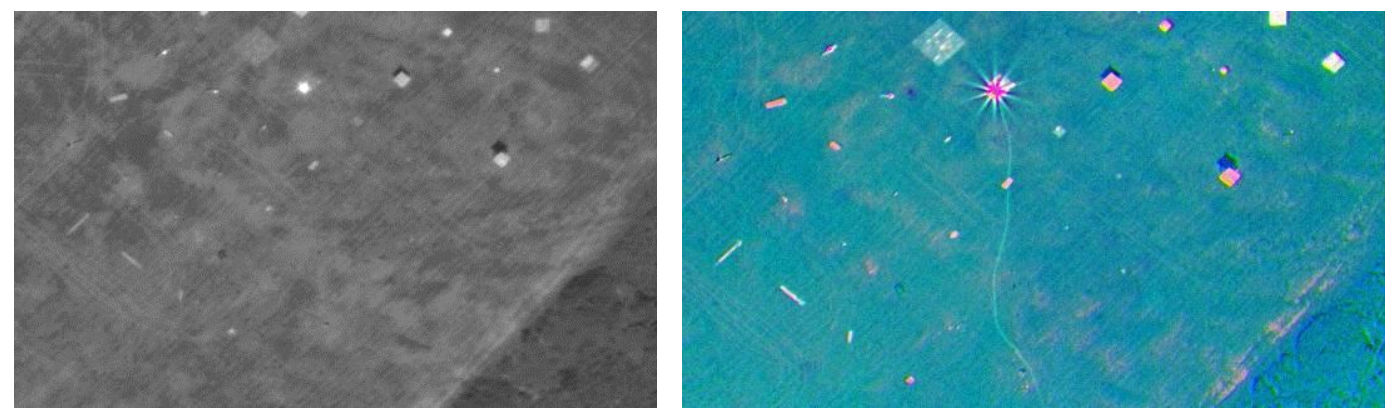

Figure 7: A pair of images showing the debris field. The intense specular reflection has generated a trailed image artefact in the CCD readout software used to create it.

\section{Harrier debris}

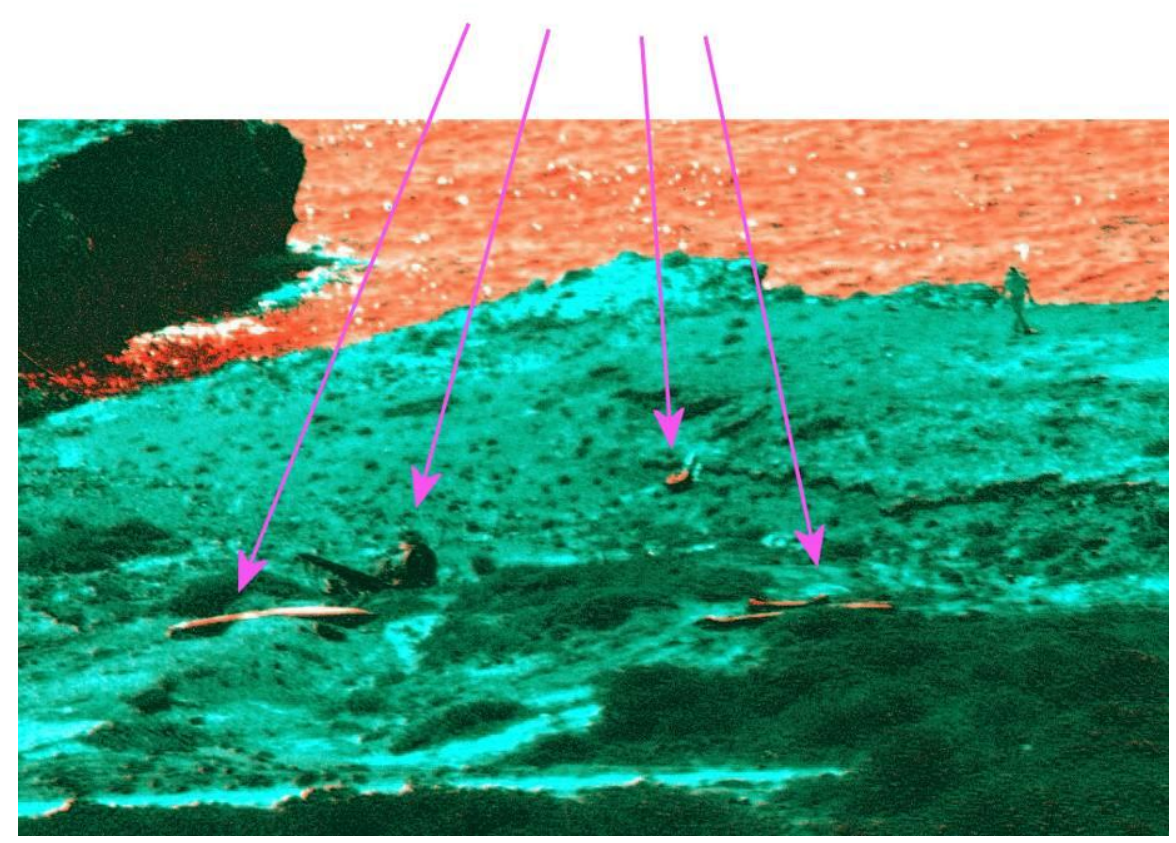

Figure 8: A false colour product of the shoreline viewed from a shallow angle. Highly polarised parts of the image are coloured red. The sea is a strong polarisation source, as are the aircraft debris seen in the foreground.

False colour composites (the basic colourised PI) showed that aircraft materials had a polarimetric response significantly different from the natural background. The painted metal fuel pods and landing gear wheel stand outclearly from the background in Figure 8. The individual in the scene (right hand edge on shoreline) was wearing cotton-based clothing which did not appear to demonstrate a significant tendency to polarise the light it reflects and so appears as a variant of the blue/green shared by the rest of the shoreline. The sea, being a strong polariser of light, is highly coloured. The remainder of the scene should appear as grey - indicating a low polarisation response - but the large area of sea visible skews the image statistics inducing a strong colour bias.

The Harrier tailplane (immediately upward and to the right of the left hand fuel pod) was blackened from the fire following its crash. Its lesser response is assumed to arise from the carbonised paint and blackened surfaces masking the response we might otherwise anticipate from metal wreckage.

An examination of the images containing the wreckage in the sea highlighted the difficulties of examining large amounts of imagery that include the littoral region. The sharp contrast in brightness between the sea and the land makes it very difficult to visually examine both in a speedy manner, without adopting an adaptive histogram equalisation or harsh 
logarithmic scaling to the display. However, in the case of PI imagery (Fig. 9), display of both image parts does not require special scaling. This permitted items on the land and sea to be evaluated successfully in the same display.

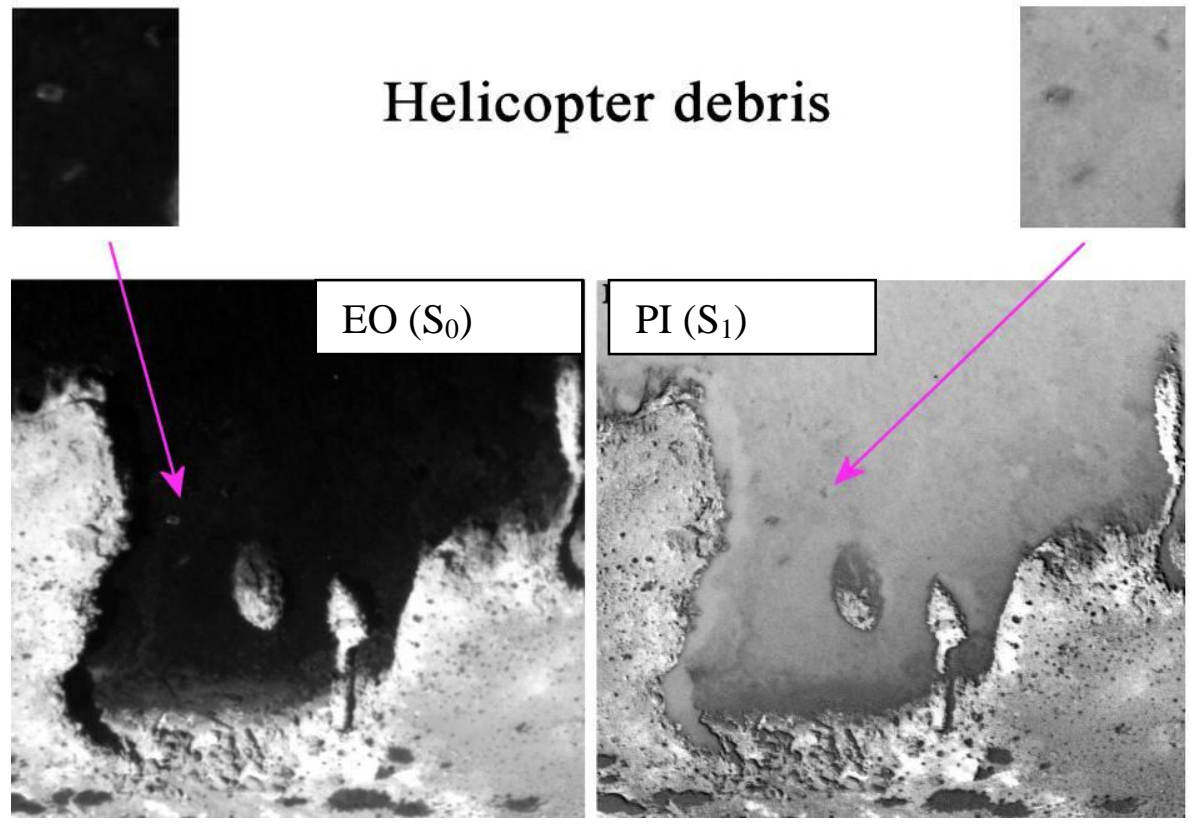

Figure 9: The difference between displaying a normal image of the shoreline and an $\mathrm{S}_{1}$ image of the same scene. The helicopter door and tail-plane are easier to spot in the PI. All scaling was automatically achieved.

As can be seen, aircraft debris was detected in the area associated with the aircrash simulation (Fig. 9). For example, the charred Harrier tail plane was immediately obvious in some view because of its characteristic profile, considerable size and darkness compared to the pale and arid surrounding soil. Unfortunately, the data from that collection was marred by limitations in the software and is considerably more sparse. There was also an unintentional bias toward collections from what proved to be comparatively poor geometries. However, in some cases the debris stood out clearly on the normal $\mathrm{S}_{0}$ imagery and so the use of PI was frequently unnecessary. The debris grid was a more challenging test, which responded well to the generation of coloured products. Especially useful was the enhancement in visibility of the smaller or transparent pieces of debris across a scene with strong variations in reflectance.

\section{CONCLUSION}

The results suggest that a handheld visible band passive PI system represents an effective low cost, upgrade and augmentation option for existing and future imaging systems in support of air accident investigation. It is suitable for analysis of the debris pattern and to focus the attention of those seeking to identify features within the pattern of the aircraft debris footprint- particularly when they lie in areas inaccessible to the accident investigator.

PI was demonstrated to have efficacy against a range of aircraft materials and to provide enhanced debris detection with PI making it easier for investigators to spot small pieces of debris that might, in standard EO imagery of a similar resolution, have been overlooked.

It has been determined that the Sun > Target > Camera geometry had an impact upon the success of such collection activities. The PI response varied noticeably, but the extent and form of this variation was not investigated. The existence of a preferred geometry was to be expected (Schott 2009) and but would have no impact upon a plan that involved normal photography from view points encircling the site. Simple tools for examining PI imagery were created and found to be effective. 
Comparatively simple tools for examining PI imagery were created and found to be effective. Consequently, PI has the potential to form part of the standard optical suite use in Air Accident Investigation search activities. In particular the ability of the polarimetric system to search wide areas for traces of debris in a non-material specific way enhances the

understanding of the debris pattern, giving a more complete picture of the event. This mapping ability also allows the team to focus their data collection on the key areas of the crash, providing better quality of data and meaning that less time need be spent in potentially challenging environments.

The result of the work undertaken by the team informed the tem making recommendations for the development of SOPs to be employed by RAF photographers at aircrash sites in denied areas. Further trials are anticipated in subsequent years.

\section{ACKNOWLEDGEMENT}

The authors would like to thank the staff of RAF Akrotiri, in particular 84 Squadron, for their sterling support during this activity.

\section{COPYRIGHT}

This paper is published with the permission of the Defence Science and Technology Laboratory on behalf of the Controller of Her Majesty's Stationery Office.

(c) British Crown Copyright DSTL/2012.

\section{REFERENCES}

Dollfus, A, Auriere, M, Optical Polarimetry of the Planet Mercury, Icarus, 23, 465, 1974.

Minnaert, M G J, Light and Color in the Outdoors, Springer-Velag, ISBN 0-387-97935-2, 1993.

O’Meara, S J, Haidinger's Brush, Sky and Telescope, Vol. 110, 7, 72, 2005.

Schott, J R, Fundamentals of Polarimetric Remote Sensing, SPIE Press, SPIE Vol. No.: TT81, ISBN 98227-0010, 2009.

Shashar, N, Rutledge P S, Cronin T W, Polarization Vision in Cuttlefish, Journal Experimental Biology, 199, 2077-2084, 1996.

Shashar, N, Hanlon , R T, Petz, A deM, Polarization Vision Helps Detect Transparent Prey, Nature, 393, 222-223, 1998.

Zhao, Y, Zhang, L, Zhang, D, Pan, Q, Object separation by polarimetric and spectral imagery fusion, Computer Vision and Image Understanding, Elsevier, 113, 2009. 
2012-09-24

\title{
Polarimetric imaging for air accident investigation
}

\author{
Privett, G. J.
}

SPIE - International Society for Optics and Photonics

G. J. Privett, M. D. Ashe, M. J. Greaves, D. Holland and L. Davidson. Polarimetric imaging for air accident investigation. Proceedings of SPIE: Electro-Optical and Infrared Systems:

Technology and Applications IX, 24-27 September 2012, Edinburgh, Scotland, UK.

http://dx.doi.org/10.1117/12.978936

Downloaded from Cranfield Library Services E-Repository 